\title{
About the Personal Creativity of the Students to Become Teachers
}

\section{Sobre la creatividad personal de los estudiantes para convertirse en profesores}

\author{
Anton Stoykov \\ stoykov70@abv.bg \\ https://orcid.org/0000-0002-7347-5408 \\ Associate Professor, PhD Trakia University Stara Zagora, Bulgaria.
}

Recibido: $12 / 05 / 21$

Aceptado: 15/07/21

\begin{abstract}
The purpose of this research is to analyze the development of the creative potential of future educators as a mandatory prerequisite for the realization of their future professional activity. For the determination of the level of development of the creative potential of students from this profile, studying in the Master's program "Preschool and Primary School Pedagogy" a Methodology is used to assess the level of creative potential of A. Sharov's personality. This methodology makes it necessary to determine by selfassessment the personal qualities and the frequency of their manifestations, characterizing the level of development of the creative and potential. Analysis of the data obtained shows that creative qualities such as "innovation", "heuristics" and "reformism" have relatively low values, related to qualities such as "purposefulness", "authoritarianism", "intelligence", "practicality". The highest value is the quality "purposefulness", which is a sign of high motivation for professional activity and is a good basis for subsequent development of creative potential. The results obtained in the course of the experimental study give reason to argue that the need for development and inclusion in the educational process with future educators of models for the development of their creative potential is up to date.
\end{abstract}

Keywords: personal creativity, higher education, development, modern teacher.

\section{Resumen}

Este artículo trata temas relacionados con el desarrollo de la creatividad personal en los estudiantes para convertirse en docentes, ya que se trata de una habilidad personal y profesional cuyo dominio garantiza el éxito de su carrera. 
Se llama la atención sobre la organización del proceso de enseñanza en la educación superior y su impacto en el desarrollo de esta habilidad. El papel y el lugar de la creatividad personal en el perfil profesional y educativo del docente moderno están fundamentados teóricamente.

Se realizó un estudio de investigación empírica y los resultados recopilados se estimaron y analizaron en términos de diferentes indicadores que describen la creatividad personal, es decir, toma de riesgos, complejidad, imaginación, curiosidad, pero también en términos de su desarrollo general.

Para ello se utilizó la Metodología Diagnóstico de Creatividad Personal de E.E. Tunic. En el estudio de investigación participaron alumnos del programa de Maestría en Pedagogía de Educación Infantil y Primaria.

Palabras clave: creatividad personal, educación superior, desarrollo, docente moderno.

\section{Introduction}

The ongoing changes in the Bulgarian education are imposing new requirements towards the higher education of the students to become teachers. These requirements refer not only to acquiring specialized knowledge, but also to the development of personal and professional skills needed for their successful professional career.

With a view to the curriculum content which is constantly undergoing updates, and the specifics of the Kindergarten and the Primary School Teacher's profession, of significant importance is the necessity of developing the personal creativity of the students to become Primary School and Early Childhood Teachers so that they are able to apply their knowledge and skills in atypical situations and to find innovative solutions to the problems arising in their occupational activity.

Modern young specialists with higher education must be prepared to deal with new challenges that require creative solutions, and be capable of creative self-development. And if the in-depth knowledge becomes a platform for training a new generation of competent professionals, the creative activity becomes a springboard which gives them an advantage in everyday activity, so at the moment the need to develop technologies shaping the creativity of students of pedagogical universities becomes mostly important. (Ormanova, et al, 2013)

N. Jackson considers that "the challenge of 'cultivating creativity in university students' is bound up with the wicked problem of preparing them and enabling them to prepare themselves, for the unknown challenges they will encounter over a lifetime of working, learning and adapting to the changing circumstances of their lives." (Jackson, 2013, p. 1).

This is related also with enreachment of the goals referring to realization of the educational process faced by the university teachers of our times. 
Efforts should not be aimed only at teaching particular professional knowledge and skills to the students, but they should also include interactions aimed at developing the student's creative approach, independent thinking and a high level of personal creativity.

It is believed that the personal creativity of the students to become teachers could develop rapidly facilitated by most of the curriculum subjects. At the same time, however, it should be highlighted that in practice professional habits and skills are being developed as a priority while creativity is left out of the picture.

Many teachers do not receive the professional training to teachcreative, because they are given mostly subject-specific area of knowledge, but not a general understanding of creativity. Encouraging creativity requires skills to adequately respond to unexpected suggestions and original ideas of children to guide and supporting their searches. Not all educators have what it takes creative attitude. (Veleva, 2012)

A. Mynbayeva, A. Vishnevskaya, Z. Sadvakassova indicate that „Creation of educational environment favorable for development of the personality of a student and his/her creative abilities is an important task of modern society. University environment is a special one; in it a student acquires profession. At the same time, creativity is a trait necessary for a professional at the time of innovations. This trait is very important for teachers who in their professional activity will be developing students' abilities and skills. (Mynbayeva, Vishnevskaya, Sadvakassova, 2016, p.408).

In the opinion of $\mathrm{O}$. Nikitin, the student's personal creativity development as an element of the educational process, would be most effective if in the educational environment conditions are created to facilitate promotion on of the individual's creativity resources: creating a safe atmosphere for the trained group of students, building a sense of mutual trust and support, compliance with the basic principles of the team work /confidentiality, voluntary-based approach, non-criticism, honesty (Nikitin, 2017).

The above suggests that the university education process should provide a possibility for professional and creative self-realization of the students. In connection with this, the issues related to development of the personal creativity in the students to become teachers, starts to create a sense of urgency.

\section{Theoretical Framework}

\section{Theoretical approaches to creative potential}

Initially, creativity was seen primarily as a function of the human intelligence and its development was associated with the individual's intellectual level. Later studies on creativity prove that intelligence is positivel y related to creativity to a certain extent only, as the higher levels of intelligence could even obstruct its development. Creativity, however, is not solely an intrapsychic phenomenon. Social and cultural factors, such as values and society norms, also contribute to the recognition and cultivation of creativity. 
Geduweb

Revista de Tecnología de Información y Comunicación en Educación • Volumen 15, Nㅜ 2. Mayo-agosto 2021

Education and the learning culture are, as well, of foremost importance for the development of the creative potential." (Alenkar, 2001, p.133) Nowadays, a main aspect in the study of creativity is its relation with the personal qualities with which it is associated.

In the modern psychological and pedagogical science, creativity is examined as a personality charecterisic in the following aspects:

- manifestation of divergent thinking;

- intellectual activity update;

- individual's integrative quality. (Nikitin, 2017)

In the opinion of ly. Zhukova, creativity is a necessary component of the socio-cultural interaction. The higher the personal creativity, the more effective is the individual's creative work. (Zhukova, 2017).

In the opinion of A. Reeves, the process of generating original and effective ideas requires:

1. Diverse inputs/inclusive thinking

2. Context articulation

3. Divergent thinking

4. Convergent thinking (Reeves, 2014)

K. Taylor points out the following indicators of creativity: productivity of thinking, activity planning skills, forecasting future actions, decision-making and decision implementation, summarizing skills. (Taylor, 1988)

According to Csikszentmihalyi, creativity can be understood as any action, idea or product changing the existing environment. (Csikszentmihalyi, 1996).

In the opnion of R. Stamatov, development of the individual's creative skills depends on:

- training - the possibility to receive training is a conmulsory precondition for the development of talents and skills. Creativity development depends on the coordination of the individual's capabilities with the possibilities for the individual's training;

- expectations - higher expectations with regard to effectiveness is a condition for the achievement of significant results;

- resources - availability of access to material and spiritual resources (access to historical models, needed materials, laboratories, libraries);

- recognition - recognition in the individual's surrounding environment is a precondition for unfolding of creativity. Non-recognition can overshadow motivation and the possibilities for a contribution. Regardless of the fact that it is not an absolute necessity, recognition is needed for objectification of the cr eative potential; 
- hope - education and training sessions in a particular field would be useless if the prospects for an effective application of the skills are bad;

- possibilities - possibilities also would facilitate development of talents and skills (e.g. talented composers in the field of classical music are very few not because there are not enough talented people, but because the possibilities for manifestation of their talent are limited);

- Internal and external rewards - better rewards (e.g. higher pay provides more possibilities for travel, meetings, better access to resources, recognition from others, insatiable curiosity curiosity) promote freedom and creativity. (Stamatov, 2015)

R. Sternberg, the author of a multi-variable approach to creativity points out the nessesary conditions and characteristics associated with personal creativity. At the beginning, he speaks about three intellectual habits: the synthetic ability to perceive problems in a new way and to avoid standard reactions; the analytical ability to assess the extent to which an idea is worth working on in the future; and the practical and contextual ability" related to the understanding of how to persuade others of the values and significance of a particular idea.

The second component of personal creativity pointed out by the author, is knowledge. In his opinin, accummulated past knowledge can prevent the search for a new approach to solve the problem, if the individual relies only on their knowledge about the problem.

The third component of personal creativity is the style of thinking.

The fourth component, in the opinion of R. Sternberg, are the individual characteristics: it is believed that creative individuals stand out with willingness to overcome difficulties, taking reasonable risk in making a particular decision.

The fifth component determing personal creativity, is motivation, and especially intrinsic motivation. It helps creative individuals in performing a certain task. This includes also the surrounding environment which can also facilitate creative decision making. (Sternberg, 2006)

From the point of view of the pedagogical science, creativity is seen as an ability to solve problem tasks in an environment of constantly changing circumstances.

Pedagogical creativity is defined as a teacher's ability, closely related to their willingness to generate new ideas with the intention to use those in order to ensure the effectiveness of the educational and training process. Teachers who enjoy a high creative potential, stand out with predominating creative thinking, the acquisition of scientific and research skills, independent analysis of the possibilities for benefiting from the achievements of the pedagogical science, active participation in the implementation of creative projects.

Beghetto, A., and Gorazza, G. reckong that "at present there is a need for more dynamic conceptions of creativity in educational settings. This is particularly important given the 
last evolution of modern society and the widespread consensus that efforts to develop creative potential should be democratized -extending well beyond the boundaries of select individuals and the confines of "gifted \& talented" programs. There is also recognition that more dynamics perspectives on creativity are necessary for understanding its complexity, value and meaning in educational contexts." (Beghetto \& Gorazza, 2019, p.2)

The future Kindergarten or Primary School Teacher is constantly facing the need to make decisions, including also decision-making in a number of atypical situations whose number is growing concidering the modern educational settings. This requires that teachers gradually develop and introduce in their communication with children a number of non-standard pedagogical solutions.

In the opinion of D. Miroshnikova, creativity of the future teacher can be seen as a "professional and personal skill, integrating pedagogical and subject knowledge, motivation to acquire new knowledge, an attempt for a creative acquisition of teaching practice, determining the readiness of the future teacher for creative pedagogical activity, forming the creative personality of the pedagogue". (Miroshnikova, 2018, page 6)

V. E. Inozemtseva, N.V. Kuzmina and L.Y. Miloradov point out the following basic skills which the creative teacher should posess: design and creative processing the material, but also his/her attitude to the ultimate goal of education; organization and support of the students' creative activity during classes and the programme as a whole; ability to analyze his/her experience in terms of finding creative solutions to the educational tasks; ability to re-adust in his/her work, to design his/her own unique system for organization of the educational content and its adjustment to the students' level of understanding. (Kuzmina, Inozemtseva, Miloradova, 1999).

According to $\mathrm{S}$. Ovcharov, formation of the creative potential of the future higher education teachers is facilitated by introducing non-traditional teaching forms and methods, innovative pedagogical technologies, organization of various psychological and pedagogical trainings, solving of professional and pedagogical tasks, active participation in scientific conferences, competitions and discussions on the problems of higher education. (Ovcharov, 2013)

Experts believe that the development of students' creativity is a multi-factor process, which includes many factors and conditions that are inextricably linked. Experts refer to the use of interactive, playful, training methods and forms in the educational process as a significant factor in the development of students' creativity. The most effective of these methods and forms, according to experts, are methods that are as close to practical activities: applied tasks, cases, business games, conferences, strategic sessions, coaching, business talks, seminars, conferences. (Matraeva, Rybakova, Vinichenk, Oseev, Ljapunova, 2020) 
S. Hwang consider that there is a connection between the work of the teacher and that of his students. They believe that the level of creativity of the teacher affects his assessment of the characteristics of students' creativity. The higher this level, the more attention he pays to these characteristics. (Hwang, 2017)

\section{Methodology}

The Methodology Diagnostics of Personal Creativity of E.E. Tunic (Fetiskin, Kozlov, Manuilov, 2002) was used to determine the level of personal creativity in the students to become teachers. This methodology studies not only the individual's personal creativity as their general skill, but also the following personal skills and qualities associated with it, in the opinion of the author, i.e. curiosity, imagination, complexity and risk taking. Among the manifestations of the main criteria and factors studied the following can be identified:

1. Curiosity. Individuals with unceasing curiosity stand out with a desire to constantly learn about new things, look for them and very often study them with the help of finding new thinking approaches/patterns/. They are looking for various solutions to nonstandard tasks.

2. Complexity. It is associated with the individual's desire to get to know complex processes and phenomena. Such individuals like to set themselves difficult tasks, to study the unknown without someone's help. They show themselves as persistent in achieving the goal they have set and often they use complex approaches for problemsolving when this is needed.

3. Imagination. For the individuals with a strong imagination it is common to see things as extraordinary, to talk about places they have never visited, to talk about phenomena with which they have not been in direct contact with. Very often they see what has been depicted in paintings or drawings in a way which is unusual for the other people.

4. Risk taking. It is manifested by the individual's attempt to stand up for his/her ideas regardless of the opinion of others. He/she always considers the risk of mistakes and failures. He/she likes to learn new things and get acquainted with new ideas. He/she often takes risks to find out what the outcome would be.

Evaluation of each of these four indicators measuring personal creativity was done on the basis of positive and negative answers, for which 2 points were received; answers partially matching the key, e.g. "maybe" received one point; and answers such as "I don't know", for which one point was taken out.

The respondends had to answer 50 statements, of which 12 were related to imagination, 12 to curiosity, 13 to risk taking and 13 to complexity.

The final quantitative assessment for each of the test indicators was determined by summing up the points for all the answers matching the key, whereas for the answers "maybe", 1 point was granted and for the answers "I do not know" -1 point was taken out. 
The higher average score describes an individual with a high level of creativity, curiosity and imagination, capable of taking risks when this is needed.

It is also possible to obtain evaluations for each of the test indicators based on the following provisional numerical rating scales:

Curiosity and Imagination Rating Scales:

$0-4$ - poor test score;

5-9 - low test score;

10-14 - moderate test score;

15-19 - high test score;

20-24 - very high test score.

Complexity and Risk Taking Rating Scales

0-5 - poor test score;

6-11 - low test score;

12-16 - moderate test index;

17-21 - high test score;

22-26 - very high test score.

Total average score:

0-20 - poor test score;

21-40 - low test score;

41-60 - moderate test score;

61-80 - high test score;

81-100 - very high test score.

The study involved 33 students from the Master's program Preschool and Primary School Pedagogy at the Faculty of Education, Trakia University, Stara Zagora, Bulgaria.

\section{Results and Discussion}

After implementation of the Methodology Diagnostics of Personal Creativity, received were results referring to the four fundamental indicators, and the total average score was estimated and analyzed.

The Diagram below presents the distribution of the total average score according to the number of students. 


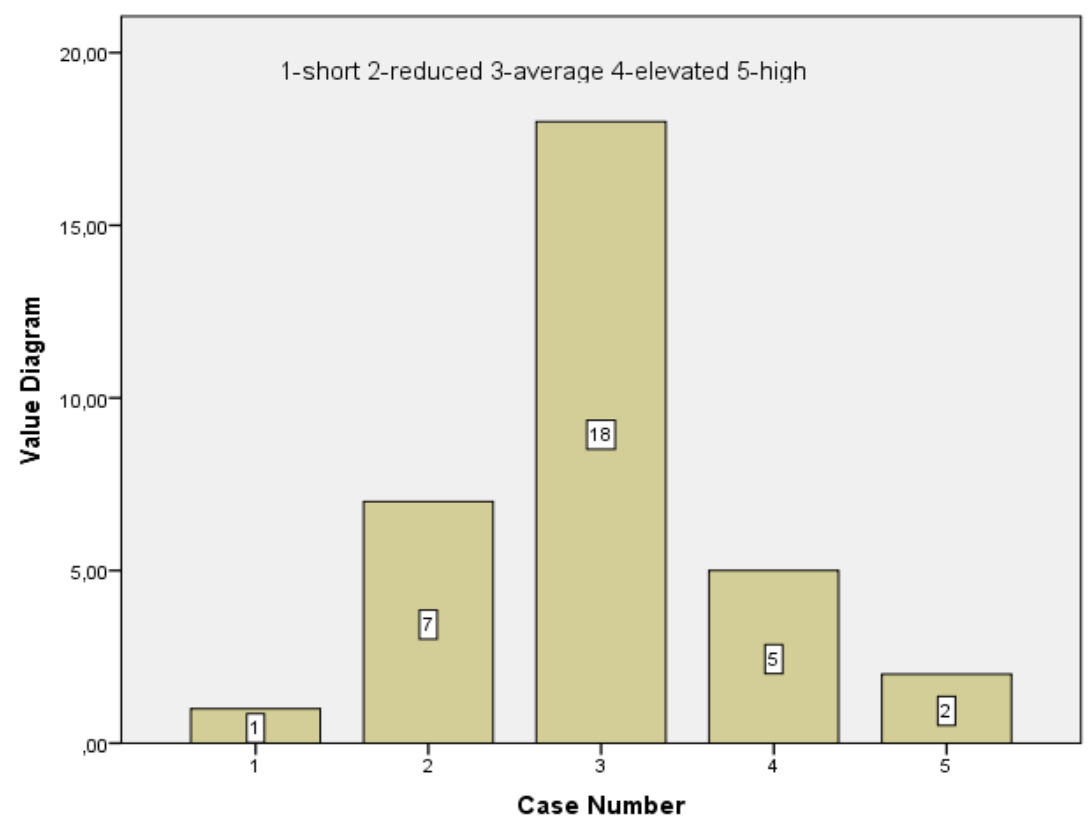

Figure 1. Distribution of the total average score according to the number of students.

The analysis of the results reveals a moderate test score for the majority of the tested students. The average total score of the tested group is 49.12 (i.e. moderate test score). This result demonstrates a moderate level of personal creativity for the members of the tested group.

Based on this result, it is assumed that in their future professional career, students will be able to achieve good results in the areas of their professional activity which require manifestation of personal creativity. Improvement of this skill at an individual level depends on the students' future activity and the characteristics of the educational environment in which they will seek realization.

The results referring to each of the rating scales based on distribution of the number of students according each test indicator are as follows:

Referring to the curiosity test indicator, the average total score is 13.48 , i.e. this is within the upper limit of the moderate test score in the rating scale. This means that the testtaking students possess pronounced curiosity. It can be seen in the student's interest in innovations in the pedagogical theory and practice, in the search for new approaches and thinking patterns, in the creative inclusion of new didactic materials into the teaching process in school and in the educational process in kindergarten. Distribution of the results according to the number of students in the Curiosity Rating Scale is presented on the following diagram: 


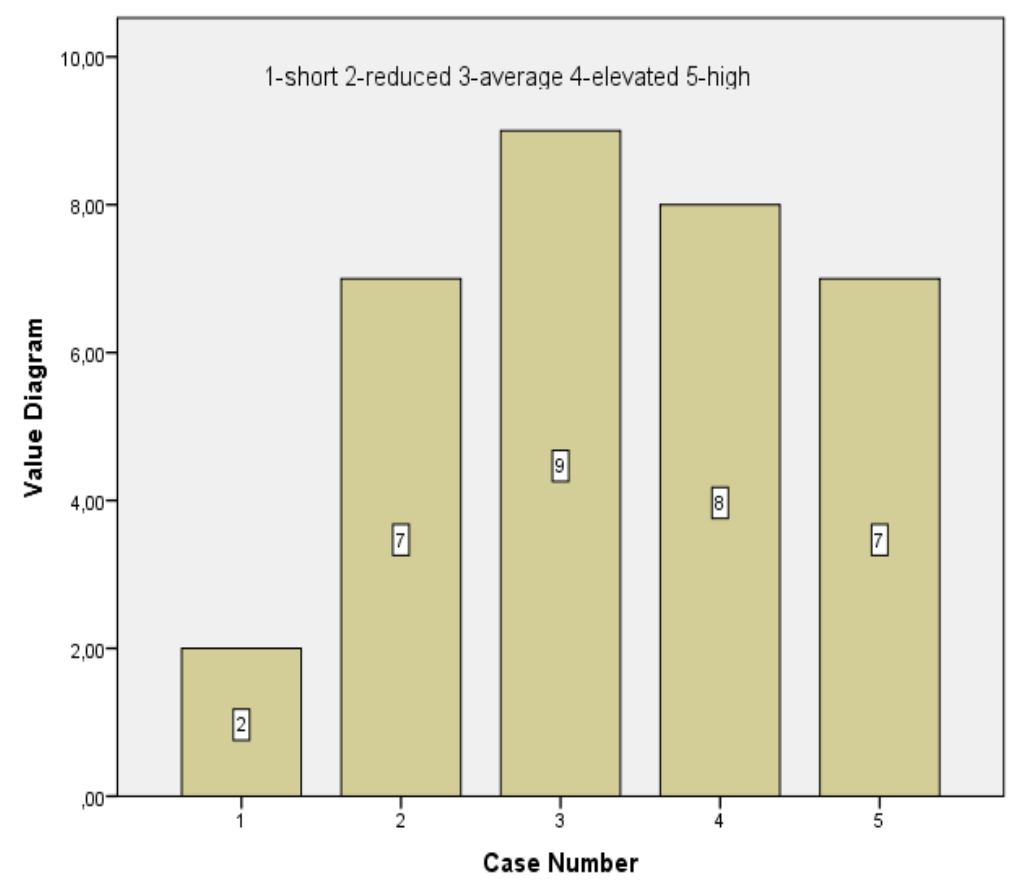

Figure 2. Distribution of the results according to the number of students in the Curiosity Rating Scale.

This diagram shows that the majority of the students have received the moderate and the high test score. Close to this number is the number of the students with very high and low test score. These results could be seen as a signal for the need to search new forms of promoting curiosity within the university education process.

Referring to the imagination test indicator, the total average score is 8.84 (low test score). This means that the imagination of the participants in the tested group is inadequately developed. Therefore, problems could be expected related to the management of creative games in kindergarten on their side, as well as to difficulties in teaching the educational content in primary school as it requires manifestation of a highly developed imagination.

Distribution of the test results according to the number of students in the Imagination Rating Scale is presented on the following diagram: 


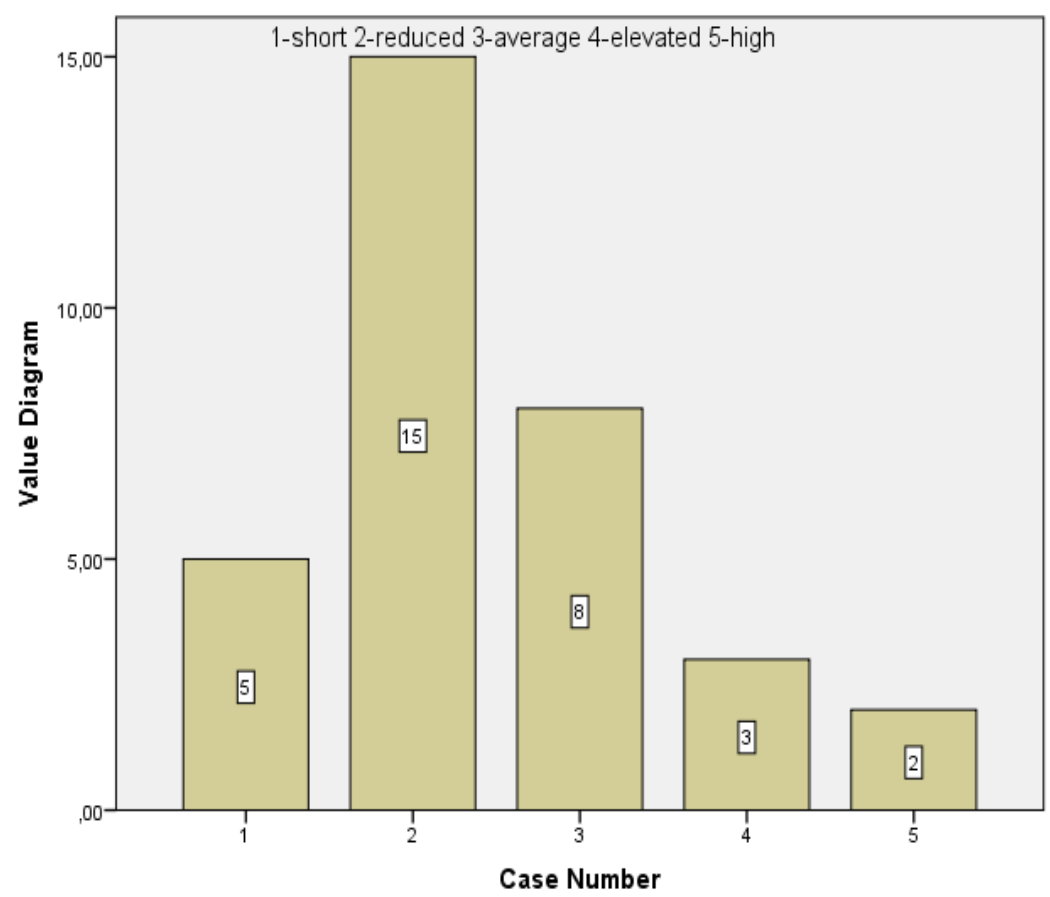

Figure 3. Distribution of the test results according to the number of students in the Imagination Rating Scale.

For the development of the students' imagination as a part of the educational process, training assignments can be introduced, as well as the method of teaching projects, promoting the students' learning activity considering their personal needs and individual qualities.

Referring to the risk taking test indicator, the total average score is 14.09 (moderate test score). This result suggests that the students tested are capable of setting themselves relatively high goals, whereas their mistakes and failures on the way to the goal achievement should not demotivate and discourage them.

This result can also be interpreted as a characteristic of the group, giving us reason to assert that the majority of the participants in the study are willing to stand up for their own opinion regardless of the risk of receiving disapproval from the others. They are willing to take risks and to see the outcome from defending their own position. Distribution of the test results according to the number of students in the Risk Taking Rating Scale is as follws: 


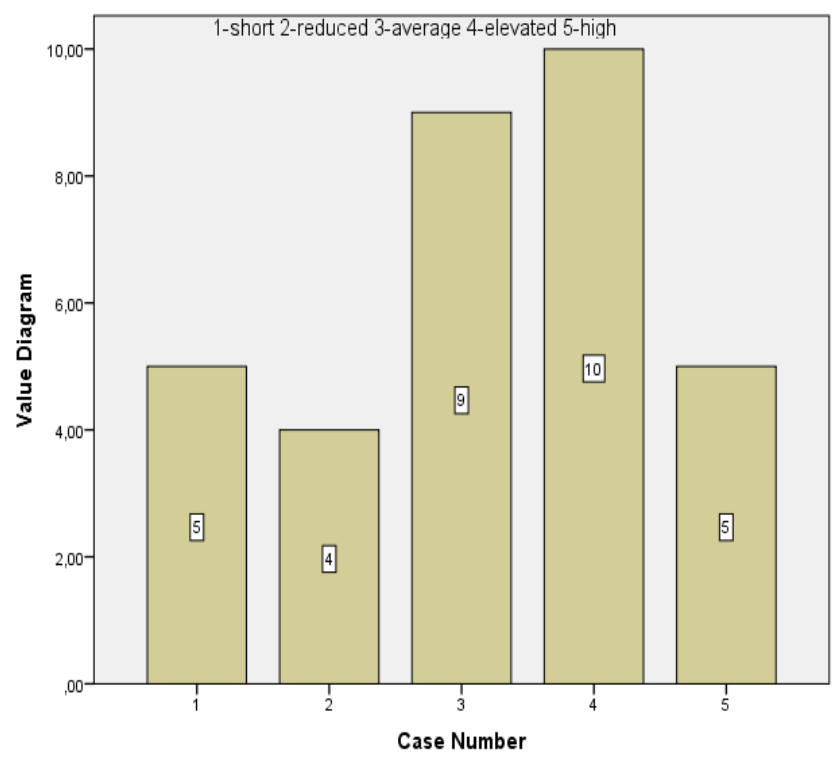

Figure 4. Distribution of the test results according to the number of students in the Risk Taking Rating Scale.

As it can be seen from the diagram, the biggest is the number of the students with the high test score, followed by the students with the moderate test score whereas the number of the students in the two groups is almost equal.

On the following diagram, distribution of the test results in the Complexity Rating Scale is presented according to the number of the students.

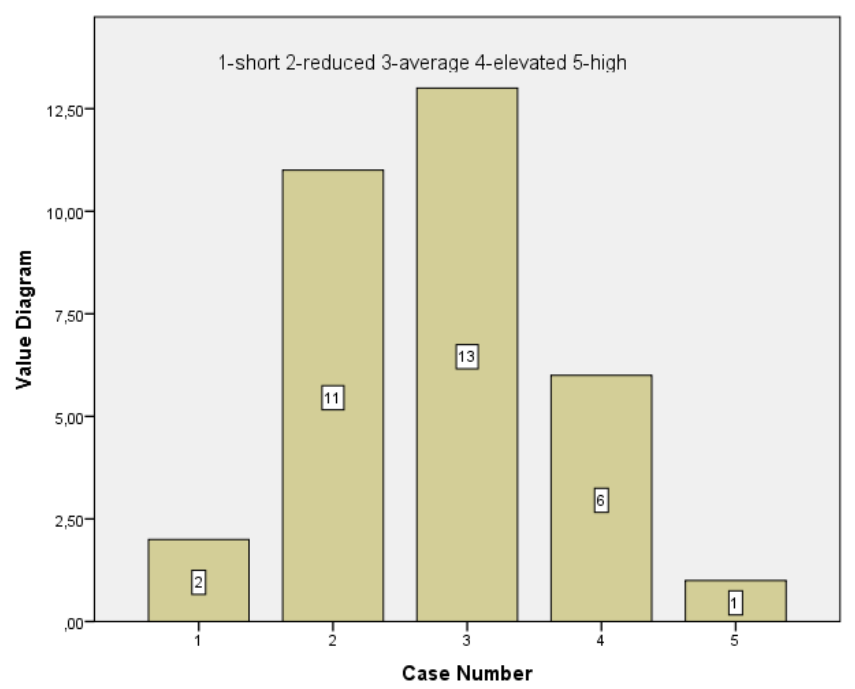

Figure 5. Distribution of the test results according to the number of the students in the Complexity Rating Scale. 
The results referring to this indicator give us grounds to assert that the test-taking students are capable of setting themselves up complex tasks and respectively achieve their implementation to some extent only. The desire to learn about complex processes and phenomena is associated with the characteristics of this indicator. Still, on the basis of the results received, probably it is not very well manifested in the major part of the students and the reasons for this should be the subject of a more profound study. The total average score for this this indicator is 12.39 (moderate test score).

\section{Conclusions}

In modern psychology, creativity is reviewed in the context of the possibilities for transformation of the world, for manifesting the latent aspects of the individual's potential, for expressing experiences and meanings (Simonton, DK (2010). Creativity in highly eminent individuals. In JC Kaufman \& RJ Sternberg (Eds.), Cambridge handbook of creativity (pp. 174 - 188) New York: Cambridge University Press/ by R. Stamatov (2015).

Based on research R. Sunley, L. Harding, and J. Jones conclude, that „higher education must provide students with creative opportunities to step across a cognitive, social and affective threshold into new knowledge and understanding about the world and themselves. This necessitates institutional support for the professional wisdom that underpins creative innovation and engagement in higher education, and acknowledges consequential implications for practice and research." (Sunley, Harding \& Jones, 2019, p.173)

The importance of studying the problem referring to the formation of personal creativity in the students to become teachers is justified most of all by the fact that it is a basis for their further manifestations of pedagogical creativity and it also facilitates the development of their creative potential. According to many authors, creativity is an objective professional requirement for the teaching profession. Moreover, it reflects the inner resource of the future pedagogues which is manifested by their skills for non-standard and constructive thinking.

The results obtained in the course of the empirical research study, related to the level of development of the personal creativity in the students to become teachers, unequivocally prove that the higher education process should be transformed in such a way as to ensure to the maximum possible degree manifestation and development of the students' creative skills and their personal creativity in particular.

This suggests that teachers should reject the stereotypical methods and techniques aimed at algorithmizing the students' actions and find more effective and efficient forms of teaching focused on developing the personal creativity of the students, related to the manifestations of creativity in their future professional activity. As early as the stage of their basic training, heuristic teaching methods should be widely used to promote the formation of the students' personal creativity. 


\section{References}

Alenkar, E. (2001) Obstacles to personal creativity among university students. Gifted Education International, 15(2), 133-140

Beghetto, A., \& Gorazza, G. (2019) Dynamic Perspectives on Creativity. Springer: Nature Switzerland AG.

Csikszentmihalyi, M. (1996). Creativity: Flow and the psychology of discovery and invention. New York: Harper Collins.

Fetiskin, N., Kozlov, V., \& Manuilov, G. (2002) Socio-psychological diagnostics of the development of personality and small groups. Publishing House of the Institute of Psychotherapy. M.

Hwang, S. Y. (2017) Rethinking creativity: Present in expression in creative learning communities. Educational Philosophy and Theory, 49(3).

Jackson, N. (2013). Developing Students' Creativity through a Higher Education.Recovery from https://www.researchgate.net/publication/321036375_Developing_Students'_Cre ativity_through_a_Higher_Education

Kuzmina, H.B., Inozemtseva, V.E., \& Miloradova, L.Ya. (1999). Higher school teacher as a subject of acmeological creativity. Acmeological problems of teacher training, No. 2

Matraeva, A., M., Rybakova, M., Vinichenko, A., Oseev. N. Ljapunova. (2020) Development of Creativity of Students in Higher Educational Institutions: Assessment of Students and Experts. Universal Journal of Educational Research, 8(1), 8-16

Miroshnikova, D. (2018) Development of the future teacher's creativity in the process of pedagogical practice. Internet magazine "World of Science", No. 2, p.6

Mynbayeva, A., Vishnevskaya, A., \& Sadvakassova, Z. (2016) Experimental Study of Developing Creativity of University Students. Procedia - Social and Behavioral Sciences, 217, 407-413

Nikitin, O.D. (2017) Pedagogical model of creative development of students of pedagogical universities. Monograph. M., $216 \mathrm{p}$.

Ormanova, G., Berkimbaev, K., Kurbanbekov, B., Ramankulov, Sh., \& Bimaganbetova, A. (2013). Formation of Creative Thinking of Students on Physics by Means of Electronic Resources. AWER Procedia Information Technology \& Computer Science, 04, p. 570-575.

Ovcharov, S.M. (2013). Pedagogical technology for the development of creativity of future teachers of informatics in the conditions of university education. Karelian scientific journal, No. 1(2).

Reeves, A. (2014) Creating Creativity: Personal Creativity for Personal Productivity. Global Innovation Science Handbook. Copyright by McGraw-Hill Education.

Sunley, R., Harding, L., \& Jones, J. (2019) Realising creativity in management education: Putting student energy into action. The International Journal of Management Education, 17. 
Stamatov, R. (2015) The Creativity. Plovdiv. ISBN 978-619-202-074-3

Sternberg, R. (2006) Creating a Vision of Creativity: the first 25 years. Psychology of Aesthetics, Creativity, and the Arts. Vol.1

Taylor, C. (1988) Various approaches to and definitions of creativity. The nature of creativity. Cambridge: Cambr. Press.

Veleva, A. (2012) Pedagogy of creativity. Printed Base Russe University. ISBN - 978 $954-712-548-3$

Zhukova, lu. (2017) Students' creativity as a pedagogical problem. deas. Search. Decisions: a collection of articles and abstracts of the $X$ Intern. scientific. practical Conf., Minsk, November 23, 2016 / Editorial board: N.N. Nizhneva (Responsible Editor) [and others]. - In 6 parts. - Part 6. 